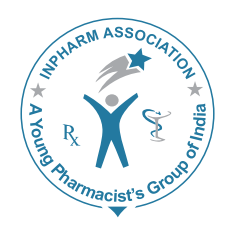

\title{
JVP
}

\section{Identifying Errors in Handwritten Outpatient Prescriptions in Oman}

\author{
Nadiya MS Al Shahaibi, Lamya S Al Said, Kini TG ${ }^{1}$, Chitme HR \\ Department of Pharmacy, Oman Medical College, Bausher Campus, ${ }^{1}$ Department of Pharmacy, \\ Muscat Private Hospital, Bausher, Muscat, Sultanate of Oman \\ Address for correspondence: Prof. H. R. Chitme, E-mail: hrchitme@ rediffmail.com
}

\begin{abstract}
To evaluate and analyze the handwritten outpatient prescriptions and associated error of omissions from four different hospitals in Oman. The study designed was an observational, retrospective and analysis of prescriptions was carried out by table and chart method. A total of 900 prescriptions were collected between April 2009 to July 2010. The type of error of omissions considered in this analysis includes all three important parts of prescriptions, i.e. superscription, inscription, and subscription. The most common type of superscription error of omission was found to be age $(72.44 \%)$ and gender $(32.66 \%)$. More than $46 \%$ of prescriptions were incomplete on direction for use, more than $22 \%$ of prescriptions were not having the information on dose, and more than $23 \%$ of prescriptions omitted the dosage forms of prescribed drugs. The date of dispensing of medications was omitted in all the prescriptions and more than $44 \%$ of prescriptions were missing the signature of dispenser. It was also found that more than $4 \%$ of prescriptions omitted the prescriber's signature and more than $18 \%$ of prescriptions omitted the date of prescription. We conclude from this study that the handwritten prescriptions were associated with significant frequency of minor and major prescription error of omissions.
\end{abstract}

Key words: Outpatient, prescription, prescription error

\section{INTRODUCTION}

A prescription drug order is a lawful written instruction from a licensed physician or other medical practitioner to a licensed pharmacist regarding the compounding or dispensing and administration of drug/s or other medical services to the patient. ${ }^{[1]}$ Prescriptions comprise of four parts. The first one

\begin{tabular}{|l|l|}
\hline \multicolumn{2}{|c|}{ Access this article online } \\
\hline Quick Response Code: & \\
\hline & Website: \\
\hline & www.jyoungpharm.in \\
& \\
\hline & DOI: \\
\hline
\end{tabular}

is the symbol for recipe that is found in the superscription, and then in the inscription specifies the ingredients and their quantities, the dosage form, dosage strength, and route of administration. The third part is named subscription in which is written the directions for compounding and in the last part which is usually preceded by sign are written the direction to be given and written on the dispensed medicine including how to take and how many and how long is the therapy. ${ }^{[2]}$ Furthermore, a prescription drug order shall contain the full name and address, gender and age of the patient and also contain the name and address with telephone number of the prescriber. Other specifications include the refills authorization, prescriber's signature, registration number for controlled drug, precaution or referral advice records to be kept. Correct prescription writing has potentially 
significant influence on the fate of medicine therapy and health of patients. Errors in prescribing may be classified into three main types: Errors of superscription, inscription, and subscription. Prescribing errors may have various detrimental consequences. ${ }^{[3]}$ Hence, the components of a prescription should be clearly written, free of drug-related omission (incomplete prescription), commission (incorrect information), and integration errors, without nonofficial abbreviations, and fulfill the legal requirements of a prescription. ${ }^{[4,5]}$

The errors of prescribing are the commonest form of avoidable medication errors and are considered to be the most important target for improvement. ${ }^{[6]}$ The process of prescription generation and dispensing is governed by regulatory systems, the purpose of which is to maximize the safety and efficacy of the product supplied. Community pharmacists have an important role in checking prescriptions to ensure that they are appropriate to dispense. ${ }^{[7}$ Many studies had identified and documented problems associated with prescribing errors. The extent of such errors varied from $2.6 \%$ to $15.4 \%$. Studies have shown that $15 \%$ to $21 \%$ of prescriptions contain at least one prescribing error. ${ }^{[3]}$ Approximately $7.1 \%$ prescribing errors were detected during the study period of 1580 medication errors at teaching hospital in Saudi Arabia. ${ }^{[8]}$ A study carried out in public teaching hospital in India has reported that $5 \%$ of prescriptions were incomplete. ${ }^{[9]}$ In Bahrain, Alkhaja et al. explored prescription errors and found $7.7 \%$ prescriptions dispensed were found to contain errors. However, $18.7 \%$ prescription errors were found in a study conducted at primary healthcare center in Riyadh city. ${ }^{[10]} \mathrm{A}$ study conducted in Indonesia by Perwitasari et al. reported a wide variation in error of omission from $0.44 \%$ to $98.69 \%$. ${ }^{[1]}$

Other studies show that pharmacists need to clarify prescriptions in $1 \%$ to $5 \%$ of prescriptions. ${ }^{[5]}$ A survey conducted in prescription errors occurring in general practice concluded that the high rate of errors was mostly as a result of handwritten prescriptions. ${ }^{\left[{ }^{[]}\right.}$As given evidence in a review of literature concludes that patient's outcomes can be improved due to the intervention of pharmacists. ${ }^{[12]}$ Another study states that not only the pharmacist's role in dispensing process is vital, policies and procedures should exist to prevent errors. ${ }^{[13]}$ Moreover, implementation of pharmacist intervention in the care of patient taking multiple medications can considerably reduce the cost, reduce adverse reactions and improve quality of life of the patient.

This study was designed to assess rates and types of handwritten outpatient prescribing errors when information is omitted. Moreover, outcome of the study reinforces the importance of prescription screening and interventions by pharmacists in minimizing preventable adverse events attributed to medication errors. ${ }^{[14]} \mathrm{It}$ also emphasizes the necessity of interdisciplinary communication and cooperation in identifying and resolving prescribing errors and irregularities in order to achieve optimal therapeutic outcomes for the patient. ${ }^{[15,16]}$ The literature review has shown no study being conducted to know about the epidemiology of prescription errors of omission in outpatients being discharged from the hospitals in Oman. The present retrospective and observational study is the first in its kind; its outcome may assist the health professional to know the frequencies and type of prescription errors of omission occurring and to think on the steps to be taken to avoid these errors in better care and safety of patients. ${ }^{[14]}$

\section{MATERIALS AND METHODS}

\section{Collection of prescriptions}

Achievement of the project involved a collection of 900 handwritten outpatient prescriptions from four different hospitals and analyzes the omissions in superscription, inscription, and subscriptions. In order to replicate normal bias working conditions as much as possible, prescribing doctors were not informed of the study. All information related to patients and hospitals were kept confidential. The study was carried out by visiting the hospitals and collecting different prescription from April 2009 to July 2010. Then, the prescriptions were divided into nine batches and in each batch there were hundred prescriptions. Each batch was contained with 100 prescriptions and filed differently with different color files to distinguish each batch. Each prescription was checked five times, once for the superscription errors; then, second for the inscription errors; third for the subscription errors; fourth for legal errors; and finally for reviewing altogether. All prescriptions were included without exclusion criteria, being these prescriptions obtained from outpatient. ${ }^{[17]}$

\section{Classification of prescribed drugs}

The prescribed drugs were checked manually with the help of tables and textbooks such as the British National Formulary and Oman National Formulary. In addition, the prescriptions were also checked consulting, Clinician's Pocket Drug References, and A to Z Drug facts. The illegibility, incorrect format, and scripts where the prescribing doctor could not be identified were also considered in prescription analysis by comparing with standards given in official formularies. The frequencies of different class of drugs analyzed in the prescription includes 
Non-steroidal anti-inflammatory drugs (NSAIDs), vitamins, antibiotics, antihistamines, nasal decongestants, analgesic, laxative, antacids, hormones, cardiovascular system (CVS) drugs, oral contraceptives, anti-emetics, antispasmodics, bronchodilators, anti-diabetics, corticosteroids, antiinfectives, etc. ${ }^{[18]}$

\section{Superscription error of omissions}

The types of errors of omissions are classified based on the information omitted on patient age, name, nationality, gender, and registration numbers.

\section{Inscription error of omissions}

The types of errors of omissions considered for inscription includes an incomplete information on dosage form, strength of medicine, dose and duration of therapy.

\section{Subscription error of omissions}

The classification of errors of omissions as subscription includes information omitted on prescriber's signature, pharmacist's signature, direction for drug use, illegible writing, and date of prescription.

\section{RESULTS}

\section{Classification of prescribed drugs}

As shown in Figure 1, a total of 900 prescriptions were collected from four hospitals of Oman, in which a total of 1471 drugs were prescribed. The range was 10 for the maximum drugs prescribed per prescription and the minimum drug prescribed was one. A variety of drugs were prescribed; however, only the drugs with frequencies higher than $1 \%$ of total prescribed drugs and for comparison purposes were depicted in Figure 1. The drug with highest frequency of occurrence was NSAIDs and analgesics (35.11\%) and the second highest category of drugs were cardiovascular (24.11\%). Furthermore, anti-epileptic, anti-hyperlipidemic, and glaucoma were drugs with the lowest frequency, 1.68\%, $1.46 \%$, and $1.35 \%$, respectively. Antibiotics, vitamins and minerals, antacids, and antiulcers were also found to be most commonly prescribed $(18.22 \%, 13.11 \%$, and $12 \%)$, respectively [Figure 1].

\section{Superscription error of omissions}

One of the most commonly omitted information was the patient's age and its frequency of occurrence was more than $72 \%$. In addition, the second most important omitted factor was gender $(32.66 \%)$. The name of the patient was present in almost all the prescriptions. However, the department of visit and registration number was almost equally omitted, i.e., $7.11 \%$ and $7.55 \%$, respectively [Figure 2].

\section{Inscription errors of omissions}

The analysis of inscription revealed that $46.33 \%$ of prescriptions omitted the direction for use of prescribed medication. In $23.11 \%$ of handwritten outpatient prescriptions, the dosage form of prescribed medication was not mentioned by the prescriber. The other important category of information on strength/dose of drug was omitted by $22.11 \%$. A significant number of inscriptions of prescriptions $(18.44 \%$ ) were also found to omit the information on dosage regimen [Figure 3].

\section{Subscription errors of omissions}

The third part was subscription which was analyzed for errors of omissions, as described in the method. Five types of omission were detected in subscription. From Figure 4 , the number of prescriber signature omitted was $4.6 \%$, while dispenser signature omitted was $44.55 \%$. However, the date of prescribed was absent in $18.18 \%$ and date of dispensed were $100 \%$ of prescriptions. The file number omitted were $8.64 \%$ of outpatient prescriptions collected [Figure 4].

\section{DISCUSSION}

The results of 900 prescription analysis found to have a total of 1471 drugs were prescribed to approximately 900 patients. The average number of medications per prescriptions was found to be 1.63 in all four hospitals. The literature suggests that frequency of error increases with an increasing number of drugs. ${ }^{[18]}$ This wide variation may be due in part to differences in definition of drug errors and partly due to problems of not reporting. The total numbers of categories of drugs found in 900 prescriptions were 35 , but only 20 categories were represented. One of the reasons for this diversity may be due to the number of doctors and the different number of departments. It could also be in line with rate of prevalence of disorders in this region. ${ }^{[1]]}$ The highest frequencies of prescriptions were found for NSAIDs and analgesic drugs, which is similar to the very recently published study. ${ }^{[20]}$

This study is a small attempt to represent prescription errors of omissions at four hospitals in Oman. It is therefore 
important to be cautious about the generalizability of the results-the study hospital may have unique features or the study time period may have been an exceptional one. The literature indicates a wide variation in estimates of medication errors and further work is needed to compare different specialties, hospitals, and countries for a true picture to emerge. However, in the present study, no effort was made to address the potential clinical significance of the errors, but it requires further study including agreement over definitions of serious and less serious errors. There is also a possibility that the prescriptions with writing errors were probably filled in haste and may therefore have been more likely to contain drug errors resulting in an underestimate of this category. ${ }^{[21]}$

As represented in Figure 4, the pharmacist's signature omitted is one of the most frequent types of error with date of dispensing. One of the reasons for omitted signature of the pharmacist could be due to the fact that most of the time the prescription is retained by the pharmacist. Furthermore, the pharmacist does not file the prescription for record; instead, they are kept in case the insurance company claims them. However, the pharmacist enters the important information into the database or system for record. Still, if the wrong medicine gets dispensed without the pharmacist's signature, the pharmacist cannot be held accountable for

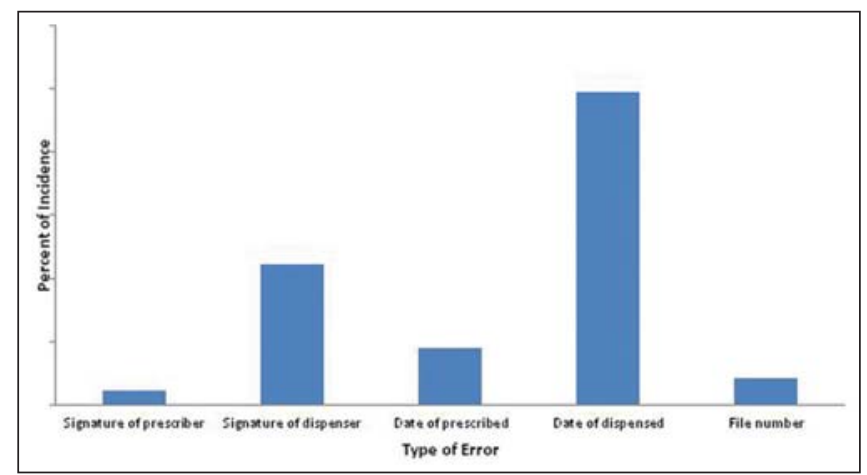

Figure 1: Classification of prescribed drugs and thier percent of occurence

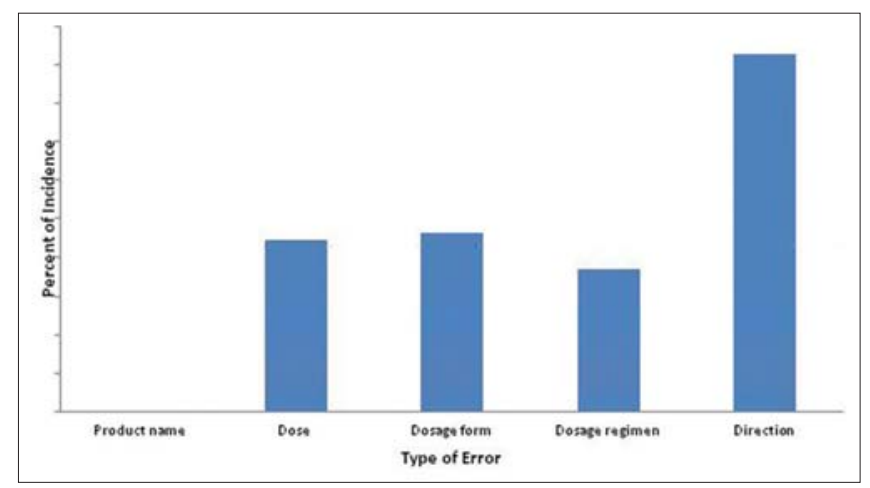

Figure 3: Percent of errors in superscription the mistake. On the other hand, the prescriber's signature is imperative, without it the drug cannot be dispensed to the patient. The rate of occurrence of this error was $4.6 \%$, which was similar to $5 \%$ and $5.1 \%$ of occurrence as reported in earlier studies. ${ }^{[5,7]}$ However, another type of error occurring considerably high is the date of prescription $(18.18 \%)$. The date of prescription is essential part of record. In case a patient suffers from an adverse reaction or the therapy is not being effective, the date could indicate when the patient started the therapy. The amount of this error in the present study was higher than the $1.02 \%$ of study carried out in India and $7.42 \%$ of study in Indonesia. ${ }^{[7,11]}$ Furthermore, $46.33 \%$ of prescriptions were with an incomplete direction which could lead to misunderstandings. For instance, some drugs are to be taken in only at night and some combination cannot be taken altogether due to some harmful interactions. Directions should be clear, complete, and should provide careful instructions to the pharmacist for the patient. The results are found to be higher than $26.43 \%$ of recently reported study, ${ }^{[11]} 25 \%$ reported by Nadeem, et al. ${ }^{[7]}$ and $25.53 \%$ of study done in teaching hospital in India. ${ }^{[5]}$ Based on a survey conducted in a general practice in US, the highest frequency of errors was due to incomplete direction or not mentioned at all, followed by the strength of drug omitted and prescribed quantity omitted. ${ }^{[22,23]}$

The prescribing of medicines is an integral part of the

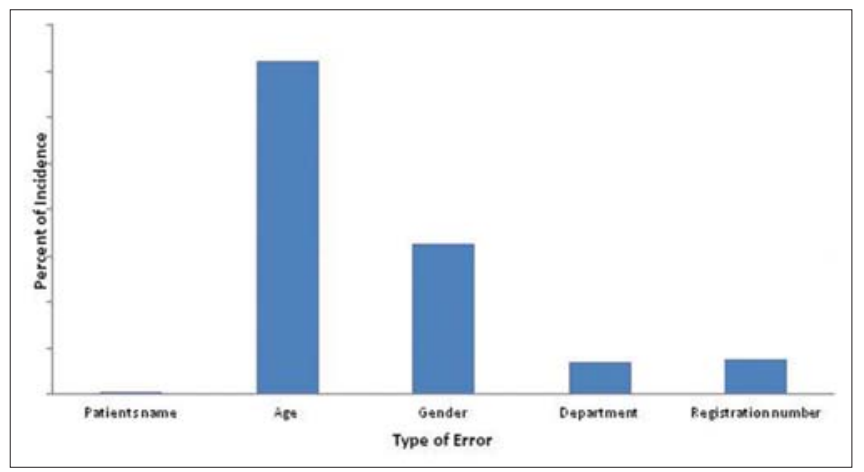

Figure 2: Inscription error of omissions in outpatient prescriptions

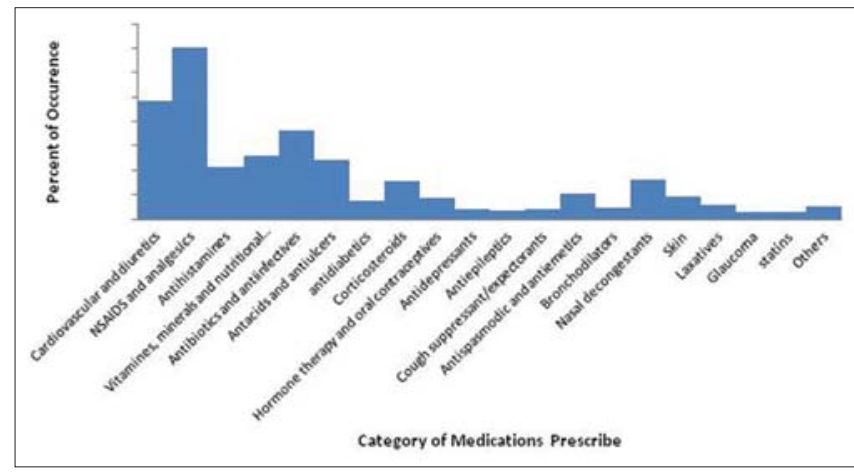

Figure 4: Subscription errors of omissions in outpatient prescriptions 
provision of health and represents a relatively safe, effective, and inexpensive mode of treatment. ${ }^{[2]}$ However, a study in the US has identified medication errors as the cause of harm in 1 to $2 \%$ of all hospital admissions. ${ }^{[25]}$ This study addresses only to links in the chain, for example, correct completion of the prescription and drug errors. We did not assess treatment decisions, follow-up, or dispensing errors as it was majorly focused on handwritten outpatient prescription analysis. However, to minimize the prescribing errors, it is important to know where they are occurring, who is committing them and in what situations. ${ }^{[17]}$ In effect, it is necessary for each specialty, hospital, or team to know where their "weak points" are in order that they can put in the appropriate defenses. ${ }^{[17]}$ This study is an attempt to identify some of the weak points in multispecialty hospitals in Oman.

The frequencies of errors of omissions in superscription, inscription, and subscription were found in most of the prescriptions. Management of all these errors is more complicated and required to use managed care pharmacy which would affect change in the healthcare system. ${ }^{[26]}$ Thorough information dissemination and education ${ }^{[27]}$ and managed care pharmacists ${ }^{[28]}$ should play a more active role in medication error-reduction activities by improving the patient and healthcare professional's education process and in assisting the medical community in its goal of improving patient safety. ${ }^{[18]}$

Totally $32.66 \%$ of prescriptions were not having the information on gender. The gender has a great impact on the medication. For example, some medications react more fast or better with female than male. So, gender play role in prescribing medication. The second highest omission in superscription was registration number and omittion of it may lead to mistake in identification of the patient. Because each patient in the hospital has his own registration number that save all patient's previous reports, in a next visit the physician may either continue with same medication or change the medication to improve the outcome or reach the target. The highest omission was age $(72 \%)$ which is very important in terms of dose and dosage form and much higher than the $52.4 \%$ of Indonesian study. ${ }^{[1]}$ These results are in line with the study carried out in Nepal. ${ }^{[14]}$

The highest number of omissions in inscriptions observed was direction for use $(46.33 \%)$ which was not clearly written, or omittion of that may lead to dispensing errors. However, $18.44 \%$ of prescriptions were without the duration of treatment and regimen which would help to reach the target and prevent adverse effects. These results are higher than the $26.43 \%, 25 \%$, and $25.53 \%$ as reported by previous studies. ${ }^{[5,7,11]}$ Omissions of medication administration like before the meals or after the meals, in the morning or with lunch, or before the bed details are reported to be potential to cause harm to the patient. ${ }^{[29]}$ The percent of incidence of this error was found to be $18.44 \%$, which was less than $26.43 \% \%^{[11]}$ of Indonesian study and $25.53 \%$ of Indian study. ${ }^{[5]}$

The present study has been restricted to only four hospitals and 900 prescriptions due to ethical concerns and other administrative restrictions. Furthermore, the prescriptions from a community pharmacy were not considered in this study as the prescriptions after being dispensed gets handed over to the patient. The evaluation and analysis of prescriptions was carried out by the graduate students as part of their graduation research project. Therefore, there may be lack of experience in identifying the drugs and directions in beginning the study, but the identification of drugs and directions was better at later half of the study.

The implications of our findings are substantial. First, it is clear that handwritten outpatient prescription errors of omission are abundant. ${ }^{[30]}$ Second, the handwritten prescription errors could be avoided by using computerized prescriptions and supportive software. ${ }^{[3]}$ Third, clinical pharmacist has a significant role to play in avoiding significant prescription errors and improve the mechanism of patient care by working together with all health professionals. ${ }^{[8]}$ Future avenues of research should focus on empowering the patient, as the constant factor, to be an active participant in the chain of responsible care. ${ }^{[16,22]}$

\section{ACKNOWLEDGMENTS}

We would like to thank Dr. Jayasekhar P, Head of Department, Department of Pharmacy Oman Medical College, Bausher Campus Muscat and Dr. Diana Beattie, Dean, Premedicine and Pharmacy Programme, Oman Medical College, Bausher Campus, Muscat for thier constant support and providing required facilities to successfully carry out the study.

\section{REFERENCES}

1. Stoll H. Physician Assistant. A guide to Clinical practice. Chapter 12 Pharmacology. The use of Medications. W. B. Saunders Company Ltd. Philadalphia, 2007. p. 206-19.

2. Haavik S, Soeviknes S, Erdal H, Kjonniksen I, Guttormsen AB, Granas AG. Prescriptions from general practitioners and in hospital physicians requiring pharmacist's interventions. Pharmacoepidemiol Drug Saf 2011;20:50-6.

3. Jeetu G, Girish T. Prescription drug labeling medication errors: A big deal for Pharmacists. J Young Pharm 2010;2:107-11.

4. Ansari M, Neupane D. Study on determination of errors in prescription writing: A semi-electronic perspective. Kathmandu Univ Med J 2009;7:238- 41. 


\section{Nadiya, et al.: Out-patient prescription analysis}

5. Marwaha M, Marwaha RK, Wadhwapadi Jyoti SSV. A retrospective analysis on a survey of handwritten prescription errors in general practice. International Journal of Pharmacy and Pharmaceutical Sciences 2010;2 Suppl 3:80-2.

6. Osborne J, Blais K, Hayes JS. Nurses' perceptions: When is it a medication error? J Nurs Adm 1999:29:33-8.

7. Nadeem SH, Mohamed A, Anthony JA. A survey of prescription erros in general practice. Pharm J 2001;267:860-2.

8. Al-Dhawailie AA. Inpatient prescribing errors and pharmacist intervention at a teaching hospital in Saudi Arabia. Saudi Pharm J 2011;19;193-6.

9. Pote S, Tiwari P, DÇruz S, Medication prescribing errors in a public teaching hospital in India: A prospective study. Pharm Pract (Granada) 2007;5:17-20.

10. Khoja T, Neyaz T, Qureshi NA, Magzoub MA, Haycox A, Walley T. Medication erros in primary care in Riyadh City, Saudi Arabia. East Mediterr Health J 2011;17:156-9.

11. Perwitasari QA, Abror J, Wahyuningsih I. Medication errors in outpatients of a government hospital in Yogyakarta Indonesia. Int J Pharm Sci Rev Res 2010;1:8-10.

12. Lewis PJ, Dornan T, Taylor D, Tully MP, Wass V, Ashcroft DM. Prevalence, incidence and nature of prescribing errors in hospital inpatients: A systematic review. Drug Saf 2009;32:379-89.

13. Amy LF, Geoghegan SR, Sowers NM, Kulkarni S, Formica RN Jr. Medication errors in the outpatient setting, Classification and Root Cause Analysis. Arch Surg 2007;142:278-83.

14. Alam K, Mishra P, Prabhu M, Shankar PR, Palaian S, Bhandari RB, et al. A study on rational drug prescribing and dispensing in outpatients in a tertiary care teaching hospital of Western Nepal. Kathmandu Univ Med J 2006;16:436-43.

15. Aronson JK. Medication errors: Definitions and classification. Br J Clin Pharmacol 2009;67:599-604.

16. Aronson JK. Medication errors: What they are, how they happen, and how to avoid them. QJM 2009;102:513-21.

17. Ridley SA, Booth SA, Thompson CM. The intensive care society's working group on adverse incidents. Prescription errors in UK critical care units. Anaesthesia 2004;59:1193-200.

18. Calligaris L, Panzera A, Arnoldo L, Londero C, Quattrin R, Troncon MG, et al. Errors and omissions in hospital prescriptions: A survey of prescription writing in a hospital. BMC Clin Pharmacol 2009;9:9.

19. Irshaid YM, Al Homrany M, Hamdi AA, Adjepon-Yamoah KK, Mahfouz AA. Compliance with good practice in prescription writing at outpatient clinics in Saudi Arabia. East Mediterr Health J 2005;11:922-8.

20. Maio V, Del Canale S, Abouzaid S. Using explicit criteria to evaluate the quality of prescribing in elderly Italian outpatients: A cohort study. J Clin Pharm Ther 2010;35:219-29.

21. Weetman T, Aronson J, Maxwell S. Reducing prescription errors. Lancet 2010;375:461-2.

22. Chumney EC, Robinson LC. The Effect of Pharmacist Interventions on Patients with Polypharmacy. Pharm Pract 2006;4:103-9.

23. Bates DW, Cohen M, Leape LL, Overhage JM, Shabot MM, Sheridan T. Reducing the frequency of errors in medicine using information technology. J Am Med Inform Assoc 2001;8:299-308.

24. Nightingale PG, Adu D, Richards NT, Peters M. Implementation rules based computerised bedside prescribing and administration: Intervention study. BMJ 2000;320:750-3.

25. Leape LL, Brennan TA, Laird N, Lawthers AG, Localio AR, Barnes BA, et al. The nature of adverse events in hospitalised patients. Results of the Harvard medical practice study II. N Engl J Med 1991;324:377-84.

26. Judy G. Towards rational prescribing. BMJ 1994;308:731-2.

27. Barber ND, Dean BS. The incidence of medication errors and how to reduce them. Clin Risk 1998;4:103-6.

28. Grissinger MC, Globus NJ, Fricker MP Jr. The role of managed care pharmacy in reducing medication errors. J Manag Care Pharm 2003;9:62- 5.

29. Bates K, Brennan TA, Laird N, Lawthers AG, Localio AR, Barnes BA. Determining the frequency of prescription errors in an Irish hospital. Ir J Med Sci 2010;179:183-6.

30. Meyer TA. Improving the quality of the order writing process for inpatient orders and outpatient prescriptions. Am J Health Syst Pharm 2000;57 Suppl 4:S18-22.

How to cite this article: Al Shahaibi NM, Al Said LS, Kini TG, Chitme HR. Identifying errors in handwritten outpatient prescriptions in Oman. $J$ Young Pharmacists 2012;4:267-72.

Source of Support: Nil, Conflict of Interest: None declared. 